\title{
Proximity and perceived safety as determinants of urban trail use: findings from a three-city study
}

\section{Jennifer R Wolch}

College Environmental Design, University of California, Berkeley, 230 Wurster Hall \#1820,

Berkeley, CA 94720-1820, USA; e-mail: wolch@berkeley.edu

\section{Zaria Tatalovich}

National Institute of Health, Building 6116-6116 Exec Blvd, 504, Mail Stop: 8315,

6116 Exec Blvd, Rockville, MD 20892, USA; e-mail: tatalovichzp@mail.nih.gov

\section{Donna Spruijt-Metz}

Institute for Prevention Research, Health Sciences Campus, University of Southern California, Los Angeles, CA 90089, USA; e-mail: dmetz@usc.edu

\section{Jason Byrne}

Griffith School of Environment, Gold Coast Campus, Griffith University, Gold Coast Campus, QLD 4222, Australia; e-mail: jason.byrne@griffith.edu.au

\section{Michael Jerrett}

School of Public Health, University of California, 50 University Hall \#7360, Berkeley,

CA 94720-7360, USA; e-mail: jerrett@ berkeley.edu

\section{Chih-Ping Chou}

Institute for Prevention Research, Health Sciences Campus, University of Southern California, Los Angeles, CA 90089, USA; e-mail: cchou@usc.edu

\section{Susan Weaver}

Solimar Research Group, PO Box 24618, Ventura, CA 93002, USA; e-mail: sweaver@solimar.org

\section{Lili Wang}

School of Community Resources and Development, Arizona State University, 411 N. Central Avenue, Suite 550, Phoenix, AZ 85004, USA; e-mail: lili.wang@asu.edu

\section{William Fulton}

Solimar Research Group, PO Box 24618, Ventura, CA 93002, USA; e-mail: bfulton@solimar.org

\section{Kim Reynolds}

School of community and Global Health, Claremont Graduate University, 180E Via Verde St, Suite 100, San Dirnas, CA 91773, USA; e-mail: Kim.Reynolds@cgu.edu

Received 2 October 2008; in revised form 25 February 2009

\begin{abstract}
In this study we focus on individual and environmental determinants of urban trail use in three diverse urban settings: Chicago, Dallas, and Los Angeles. Explanatory factors include individual psychosocial and health characteristics, distance between home and trail, and land-use and social characteristics of trailside neighborhoods. Model results suggest that intrinsic motivation, general health status, perceived trail safety, perceived miles between home and trail, and neighborhood connectivity were significantly related to probability of trail use and extent of trail use, while workingclass status, commuting distance, and physical barriers to the trail were negatively related. Efforts to increase perceived trail safety, accessibility, and awareness about trails thus may result in a higher rate of trail use and more time spent on urban trails.
\end{abstract}

\section{Introduction}

A substantial body of literature suggests that sedentary lifestyles and associated health problems - such as obesity, diabetes, and heart disease (Anderson et al, 2005; Calle and Kaaks, 2004; Deckelbaum and Williams, 2001; Janz et al, 2005) — may be linked to urban sprawl, generally, and to specific characteristics of the social and built environments of cities (Ewing et al, 2003; Frank et al, 2003; 2004; Handy et al, 2002; Jackson, 2003; Lopez, 2004; Lopez-Zetina et al, 2006). Efforts to explain the impacts 
of urban form on physical activity, including the effects of access to recreational facilities and opportunities for walking and bicycling, are part of larger crossdisciplinary nitiatives to promote active living (Godbey et al, 2005; Hoener et al, 2003; Lee and Moudon, 2004; Sallis et al, 2000; Srinivasan et al, 2003). These efforts, in turn, may inform urban planning decisions, including investments in parks, recreational centers, and other infrastructure designed to maximize physical activity, improve health, and enhance the overall quality of life in urban settings (Dannenberg et al, 2003; Frumkin, 2003; Groenewegen et al, 2006).

Urban trails are key components of the built environment that may influence physical activity. Trails are multiuse paths designed for walking, bicycling, skating, horseback riding, and other forms of recreation or nonmotorized transportation. They are typically paved with asphalt, or compressed stone dust, and pass through diverse landscapes, including lakefronts, woodlands, and ocean shorelines. Urban trails also traverse through a range of urban land uses including industrial, commercial, and residential areas.

Studies of urban trails generally suggest that experiencing nature, exercising, recreation, and commuting are the primary motivations for urban trail use (Gobster, 1995; Huston et al, 2003; Lindsey and Nguyen, 2004; Troped et al, 2001). Trails may make exercise more convenient, offer pedestrians and cyclists alternatives to motor vehicles, increase the mobility of those who cannot drive, and link workplaces, homes, schools, parks, commercial facilities, and cultural centers. Trails may also serve as corridors to parks and playgrounds, opening up a network of recreational opportunities for leisure and outdoor activity, and enhance the access of urban dwellers to nature. Thus, urban trails represent a multidimensional type of public open space that can be expected to influence physical activity and health, as well as to shape urban form, enhance urban ecological functioning, and promote a sense of community pride and identity. Existing scientific knowledge about trail use patterns and their correlates, however, is still fragmented and insufficient to inform trail infrastructure investment decisions or to shape strategies to maximize multiuse trail activities (Gobster, 2005; Krizek et al, 2007; Lindsey et al, 2006; Reynolds et al, 2007). While some studies support a relationship between proximity to trails, frequency of use, and/or physical activity (Brownson et al, 2004; Wolter and Lindsay, 2001), other studies - including Evenson et al (2005) who studied Durham, North Carolina residents in neighborhoods proximate to a rails-to-trails project before and after conversion-have shown no demonstrable link to physical activity.

We report on relationships between multipurpose urban trail use and features of the social and built environments. The analysis builds on the work of Reynolds et al (2007), who analyzed trail characteristics as determinants of the volume of trail use in Chicago, Dallas, and Los Angeles. Residents of trail-adjacent neighborhoods in these three cities were surveyed about their sociodemographic and economic characteristics, trail use patterns, and their perceptions of the trail and its environs, while trailside neighborhoods were characterized through various measures of the social and physical environment. Results indicate the extent to which both individual-level and neighborhood-level variables influence the use of urban trails by those living in proximity to them. Findings inform efforts to maximize the use of existing trails as well as the design of future urban trails.

\section{Conceptual framework}

Existing research reveals considerable variation along multiuse trails in both types of activities and numbers of users. For example, Hunter and Huang (1995) reported substantial variation in the volume of trail use ranging from a low of 25 users per 
hour on the Iowa Heritage Trail, a rural trail, to a high of 240 users per hour on urban trails in New York. Lindsey and Nguyen (2004) found significant intratrail and intertrail variations over different times of the day, days of the week, and seasons at five greenway trails in Indiana. In a different study, Lindsey (1999) estimated that monthly use ranged from 2500 users on the White River Trail to 41500 users on the Monon Trail in Indianapolis.

What is responsible for differences in trail use, particularly among residents who live in trailside neighborhoods? Conceptually, the explanatory variables may be grouped into four categories: individual characteristics, including distance from the trail; features of the user's built environment, such as the availability of competing leisure and physical activity opportunities, attractiveness, or connectivity; social characteristics of trailside neighborhoods, including socioeconomic status; and the trail environment itself (condition, crowding, safety) (figure 1). More general features of the environment, especially weather, no doubt also play a major role. During very hot weather or inclement and/or cold weather, trail use is apt to decline, and such weather may influence trail use differentially (older people, for example, might not wish to exert themselves on very hot or cold days). In many cases perceptions are as important as objective characteristics. For example, individual perceptions of their own health status and motivation to be physically active may be as or more critical as demographic characteristics typically associated with trail use such as race or gender; perceptions of trailside neighborhood attractiveness and social mix, or about trail safety, may be more predictive of trail use than data on land-use mix (LUM), socioeconomic status, or crime rates. Note that these categories span three spatial levels or extents (individual, neighborhood, and the trail itself).

Prior studies suggest that trail users are predominantly male, white, young to middle aged, wealthy, well educated, live in households without dependent children, and typically reside within five miles of the trail (Furuseth, 1989; Furuseth and Altman, 1991). Certain characteristics of the user environment, such as neighborhood aesthetics, traffic density, and road crossings, have also been identified as predictors of trail use. Typically, trail use volume and frequency are greater in neighborhoods that are aesthetically pleasing, and in areas characterized by greater traffic density (Furuseth and Altman, 1991). Variations in urban trail use are also a function of the

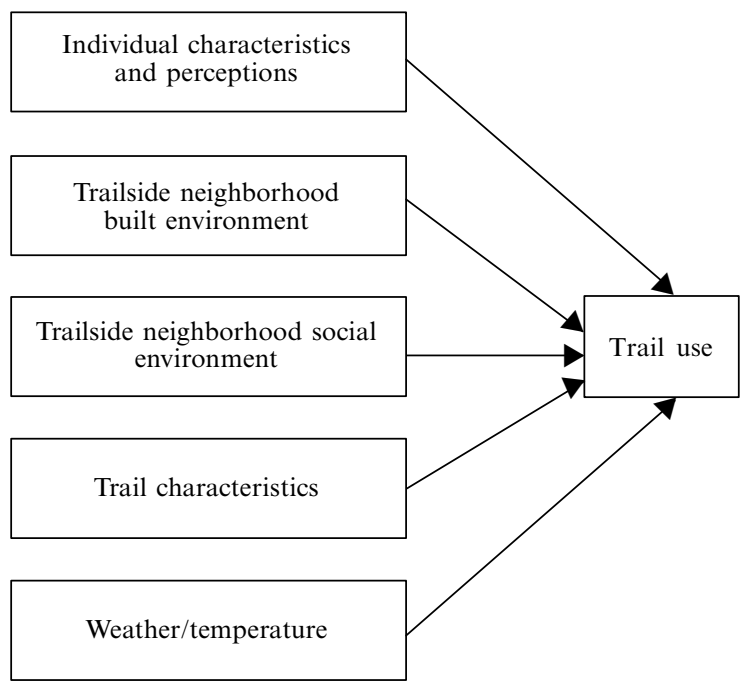

Figure 1. Conceptual model of the trail use. 
social environment, specifically its sociodemographic characteristics, perceptions of personal and neighborhood safety, crime rates, and the presence of community support and cohesion. Neighborhoods that are perceived as safe, where crime rates are lower, and where there is greater community support and cohesion are more inviting to trail use activity (Hunter and Huang, 1995; Lindsey and Nguyen, 2004; Reynolds et al, 2007). There is also preliminary evidence that trail use may be impacted by the physical features of trail and immediately proximate neighborhood settings, specifically trail location and accessibility, trail-adjacent land uses, trail surface materials and condition, vegetative health, natural areas adjacent to the trail, and the availability of parking (Lindsey et al, 2006; Reynolds et al, 2007).

The current body of evidence is still relatively weak, however. It is likely that many interacting individual-level and neighborhood-level characteristics influence urban trail use. Thus far, few studies have attempted to combine data on individuals, physical activity infrastructure, and the neighborhood environment to explore their interactions. We examine the impact of individual characteristics, neighborhood social and built environments, and trail-level influences on trail use simultaneously, using a multilevel approach designed to help identify and characterize the relevant individual and urban contexts that promote trail use and associated physical activity. We hypothesize that decisions to use urban trails, as well as the extent of trail use, are related to demographic characteristics as suggested by past studies - positively related to higher intrinsic motivation to be active, better general health status, and greater proximity to a trail. We expect that neighborhood connectivity and other aspects of the built environment that promote walkability such as sidewalks and tree canopy, and perceived attractiveness of streetscapes, may encourage trail use. Since neighborhoods that are (for example) leafy and attractive are typically associated with higher socioeconomic status, we also expect related neighborhood social characteristics to be positively linked to trail use. Lastly, a key aspect of the trail itself - safety - is expected to matter, with respondents who perceive trails to be safer being more apt to use the trail.

It should be noted that, like all cross-sectional studies, this analysis cannot shed light on causality. Thus, for example, we are not able to discern whether those with better general health status use the trails more because they are in better health, or whether their health status stems (at least in part) from trail use and associated physical activity. Similarly, there is the 'who came first' dilemma, or residential selection bias. Some trailside residents may move into the neighborhood in order to be close to, and use, proximate trails, rather than being prompted to use them because of their proximity once built. Only two urban trail use studies indirectly address this question, by investigating resident awareness of trails in their neighborhood following construction of a new trail; in one case postconstruction awareness was low [34\% (Merom et al, 2003)], and, in the other, less than a quarter of residents were aware of the trail and had used it once (Evenson et al, 2005) - thus the role of trails in attracting residents may be relatively low. However, such questions are vital, and can be addressed only by careful longitudinal analysis that combines objective measures of physical activity as well as a variety of explanatory factors designed to capture individual characteristics and perceptions, physical and social characteristics of trails and trailside neighborhoods, and ambient environmental qualities that influence outdoor physical activity.

\section{Methods}

Methods include trail selection, trail segment delineation, empirical assessment of trailside neighborhood characteristics, and surveys of residents living in trailside neighborhoods. Together, these methods allowed us to create variables associated with the key aspects of the conceptual framework: individuals and their objective demographic 
characteristics as well as their perceptions of their own health and motivation to exercise; perceived and objective neighborhood social features as well as built environment characteristics; and trail characteristics as perceived by trailside neighborhood survey respondents. The analysis incorporated both multilevel modeling that enabled examination of the combined influence of the individual-level and neighborhood-level variables on the individual trail use outcomes, and a unilevel model that provides insight into both use or nonuse decisions and decisions about how much time to spend on the trail. The statistical procedures were conducted in SAS (version 9 SAS Institute Inc. 2004).

\section{Trail selection procedures}

Trail selection was accomplished using carefully defined criteria that ensured diversity of climate across trail sites, variability of metropolitan form (auto-orientation), and race/ethnicity and income of the population in the areas traversed by each trail. The initial list of trails was composed of over a thousand potential candidates located across the continental US. They were identified using a web-based search, and databases from the Rails to Trails Conservancy, the National Transportation Enhancements, Coalition for Recreational Trails, and National Recreation Trails. The selection of candidate trails was based on the following a priori criteria:

- availability to multiple users;

- location within large metropolitan area;

- representative of different climatic regions;

- minimum uninterrupted length of fifteen miles;

- traverse neighborhoods with at least two of the following racial or ethnic populations: African-American, European-American, or Hispanic; and

- funding from the Intermodal Surface Transportation Efficiency Act.

Trails governed along their entire length by a single jurisdictional entity (eg city, county, park authority) were also given priority for selection, although many major trails traverse more than one municipality.

Three shared-use trails were identified in climatically different urban areas of the United States. The selected trails included: (1) Chicago Lakefront Trail, Chicago, Illinois; (2) White Rock Lake Trail, Dallas, Texas; and (3) the southern portion of the Los Angeles River Trail, Los Angeles, California.

\section{Trail delineation procedure}

The three trails were delineated into 102 half-mile long segments (Chicago, $n=34$ segments; Dallas, $n=30$ segments; Los Angeles $n=38$ segments) using a geographic information system (GIS)-ArcGIS 8.0 (Environment Systems Research Institute, Redlands, CA). Two maps were created for each segment, one with street names and one with aerial photography of surrounding areas. The trail was superimposed on each map. Each map covered a separate segment, and latitude and longitude coordinates for the start and end points of the segments were provided on the map. Coordinates generated using the GIS were 'ground truthed' using a hand-held global positioning system.

\section{Trailside neighborhood assessment}

The neighborhood assessment highlighted the objective measures of sociodemographic and physical characteristics of trailside neighborhoods. Conceptually, different combinations of demographic, racial and ethnic, socioeconomic, and physical characteristics of the trailside neighborhoods may have differential impacts on trail utilization. For example: traversing wealthy as opposed to impoverished communities may be more congenial for trail users; neighborhoods that are more connected may 
offer better access to trails through a network of linked streets, landmarks, and other built-environmental features; diversity of land-use types and the presence of parks in urban neighborhoods comprise a set of opportunities that may affect the types and amounts of movement possible or desirable in that environment, including the use of urban trails; certain natural features such as rivers-or built environmental features such as railroads, freeways, or rivers - may place barriers to trail access, and therefore affect trail use outcomes.

Although crime rates were originally identified as an important neighborhood feature that could influence trail use, problems with obtaining crime statistics for a number of the jurisdictions through which the three trails run prevented the inclusion of a crime variable. A total of sixty-eight variables were collected at the census tract level and were subsequently reaggregated to the trail segment level. After all of the computation and normalization of data (percentages, or density functions), the sixty-eight independent variables were grouped into fourteen conceptual categories: eight of these categories were intended to capture the sociodemographic profile of the trailside neighborhoods (age, race, ethnicity, income and poverty, housing type, housing tenure, vehicle ownership, and commuting time) and the other six conceptual categories were chosen to characterize the built environment that surrounds the trail sites (total jobs and businesses, LUM, connectivity, barriers to trail access, transportation opportunities, and green cover; see table A1 in the appendix).

The neighborhood assessment relied on the use of principal component analysis (PCA). This data-reduction procedure grouped the variables from each of the fourteen conceptual categories into a smaller number of factors. The factors were initially used to empirically characterize the neighborhoods that surround the three trails, described later. Subsequently, we examined the relative influence of the neighborhood-level factors, in combination with the individual characteristics obtained from the survey, on urban trail use outcomes.

\section{Survey of trail use}

A survey of trail use was performed in a sample of 490 trailside neighborhood residents - 186 in Chicago, 161 in Dallas, and 143 in Los Angeles (Spruijt-Metz et al, forthcoming). The instrument included items on: (1) extent and purpose of trail use; (2) sociodemographic attributes including race and ethnicity, income, education, and household type; (3) motivation for physical activity and self-reported health status; and (4) perceptions of the trail environment including distance to the trail, neighborhood safety, trail safety, access to services, social cohesion, and neighborhood surroundings.

The extent and purpose of trail use were measured using a self-report survey with closed-ended and brief open-ended response formats. Distance of the selected trail and the time required to reach the trail from home and work were assessed. The number of times per month the trail was used, and the typical activity engaged in on the trail (eg walking, biking), the average distance traveled, and the average time spent during each use were asked separately for recreational use and transportation use. Recreational-related and transportation-related reasons for use of the trail were defined and respondents indicated the main reason they use the trail for recreation (eg to reduce stress) and transportation (eg to avoid the cost of transit fare).

Motivation for trail use was measured using three items and a seven-point response scale ranging from 1 'Not at all true' to 7 'Very true'. Each of the three items represented a reason that respondents would have for using the trail. Respondents were asked "Please indicate how true each of these reasons is for why you exercise regularly". The reasons included "Because I enjoy exercising", "Because it is a challenge 
to accomplish my goal", "Because it's fun", and "Because it is interesting to see my own improvement". Perceived health was measured by asking each respondent "In general, compared to other people your age, would you say your health is excellent, very good, good, fair or poor" and respondents could check the box corresponding to this rating.

For the perception measures individuals rated a series of statements within each scale using a point response format that ranged from 'strongly disagree' to 'strongly agree' with the exception of social cohesion that also included a response option for 'neutral' between 'somewhat disagree' and 'somewhat agree'. The neighborhood safety scale used three items to ask about traffic on nearby streets, lighting on neighborhood streets, and perceived neighborhood crime. Trail safety used six items asking about lighting, ability to see the trail from houses adjacent to the trail, presence of others on trail, perceived crime on the trail during the day and night, and animals on the trail as a threat to safety. Access to services used three items and asked about places within $10-15$ minutes walking distance of the home, ease of walking to a transit stop, and difficulty of walking in the neighborhood due to hills. Social cohesion provided five items asking about the willingness of neighbors to help one another, whether the neighborhood is 'close knit', and whether neighbors can be trusted, generally get along with each other, and share the same values. The measure of neighborhood surroundings assessed perceived aesthetics and asked whether there are trees along the streets in the neighborhood, interesting things to look at while walking in the neighborhood, and whether the neighborhood is generally free of litter.

The analysis of survey data supplied information on the reported trail use patterns including the percentage of trail users and nonusers, and the percentage use for transportation and recreation purposes for each candidate trail. In addition, questions concerning the average number of times the trail was used per week, plus the average time spent on the trail per visit, were used to create a time on trail per week variable.

\section{Development of statistical models}

At the outset we used the Pearson correlation procedure to examine the individuallevel and neighborhood-level correlates of trail use as measured by total time spent on the trail. The individual-level variables were obtained from the survey and included intrinsic motivation for physical activity, general health, and a set of variables based on perceived availability of recreational facilities, streetscape quality, quality of neighborhood surroundings, social cohesion, neighborhood safety, trail safety, access, as well as distance to trail. The neighborhood-level measures included the components from the PCA analysis that explained the greatest percentage of variance among the trail segments from each of the fourteen conceptual categories: age, race, ethnicity, income and poverty, housing type, housing tenure, vehicle ownership, commuting time, total jobs and businesses, land-use mix, connectivity, barriers to trail access, transit opportunities, and green cover. The Pearson correlation coefficients informed the selection of variables for input into models, whereby the variables with the highest coefficient $(r)$ with total time of trail use were considered first.

Two sets of models were run. First we explored the individual-level and neighborhood-level influences on the likelihood of trail use or nonuse with a multilevel logistic regression model run with the GLIMMIX (generalized linear mixed model) function using different combinations of individual-level and neighborhood-level variables. Those independent variables that had the highest $p$-value were excluded from analysis and the procedure was reiterated until we arrived at a model specification in which the majority of independent variables were significant. Significance was set a priori at $p<0.05$. Two dummy variables were included to account for the effect of city, one for Chicago and one for Dallas, with Los Angeles used as the control city. 
Next, we explored the factors that may influence the amount of time spent on the trail through a series of Tobit regression models. Tobit models are appropriate in instances where there is a substantial number of zero values in the dependent variable (in this case, time spent on the trail); the procedure considers these zero values and minimizes the bias in the results. In the present context, although not a multilevel model, the Tobit model was useful in providing insight into the effects of independent variables on total time spent in trail use (among trail users), and on the probability that the nonusers (zero cases) would start using the trail were the values of the independent variables to change.

\section{Results}

The results are presented in three subsections. The first describes the three trails based on the sociodemographic and physical characteristics of the trailside neighborhoods that were identified through the PCA analysis. The second phase provides information on individual trail use patterns and describes the differences between trail users and nonusers on the basis of the results of analysis of the survey data. The third and the most extensive subsection presents the results of the multilevel logistic and Tobit modeling of the impact of individual-level and neighborhood-level variables on individual trail use outcomes.

\section{Empirical description of the trailside neighborhoods}

The empirical description of the trailside neighborhoods was based on the results of the PCA analysis. The PCA grouped all the variables associated with each conceptual category listed in table A1 into smaller numbers of factors (or components). The individual factor loadings per trail segment were used as the basis for understanding patterns of sociodemographic and built-environmental characteristics in the neighborhoods that surround the Chicago Lakefront Trail, Dallas White Rock Lake Trail, and Los Angeles River Trail, respectively. Each trail was mapped; in the case of White Rock Lake, the shaded area on the map indicates the extent of the larger park through which the trail meanders. Additional qualitative information on each trail and adjacent neighborhoods was also collected from secondary sources.

(1) Chicago Lakefront Trail (figure 2), the most scenic of the three trails, runs along Lake Michigan, through the heart of the city, the Loop, and passes important landmarks such as Millennium Park. The facility is managed by the city's park department, and as a major destination for tourists as well as residents it is attractively landscaped, well maintained, and policed. It is also the most diverse in terms of built environment and ethnoracial mix. The trail begins north of the uptown neighborhood, near Highway 14, and ends just before 71st street-near the neighborhood of South Shore. The trail also passes through diverse landscapes passing close to the skyscrapers of downtown Chicago, over the Chicago River, and past aquariums, museums, sports complexes (eg Soldier Field), a university campus, beautifully landscaped ornamental parks, bird sanctuaries, sandy beaches, playing fields, and the tourist attractions of Navy Pier. Most of the residential landscape consists of multistorey apartment buildings though some lower density housing is found in the southern reaches of the trail. Many urban scholars would immediately recognize the neighborhoods of the Gold Coast, New Eastside, and Prairie Avenue district as well as numerous parks like Grant Park with its famous Buckingham Fountain - all located in close proximity to the Lakefront Trail. In terms of demographics, neighborhoods in the northern and southernmost sections of the trail are predominantly Asian and other races (a census category that includes Hispanics), multifamily, and long-distance commuter areas. The central portion of the trail is characterized by African-American population, 


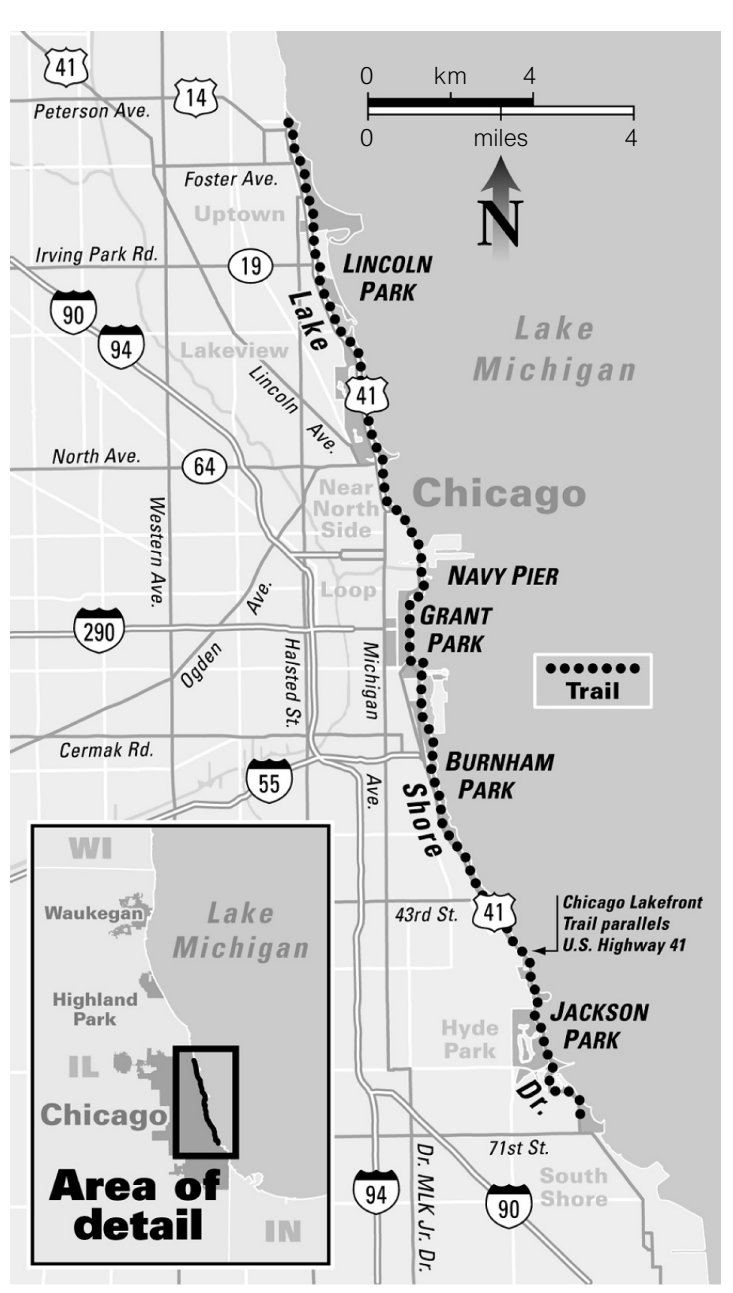

Figure 2. Map of Chicago Lakefront Trail.

working-class residents, and families with children and young adults, with ready job access. These neighborhoods are also characterized by a diversity of land uses, parks, and schools, significant opportunities for transit use, but also substantial physical barriers to easy trail access.

(2) The Dallas White Rock Lake Trail (figure 3) is situated in the middle of Dallas, and runs through neighborhoods that - like the city as a whole - tend to be suburban in character and do not traverse any major built-up areas even though it is close to downtown Dallas. Arguably the greenest of the three trails, the White Rock Lake trail begins in Valley View Park adjoining the L B Johnson Freeway (I635) and then parallels the White Rock Creek before encircling its namesake lake. The trail passes through parkland for most of its length and large sections of the trail are up to a quarter of a mile from adjoining neighborhoods. The trail, completed in 1976, is relatively well maintained, and winds through a varied landscape including the lake edge itself, wooded areas, parklands, and both residential and commercial areas. The trail passes through the east Dallas suburbs of Bouchard, White Rock, and Rawlins before heading south. On the Lake's western perimeter, the trail passes through: Lower Grenville (an entertainment district with fashionable bars, restaurants, and boutique stores); 


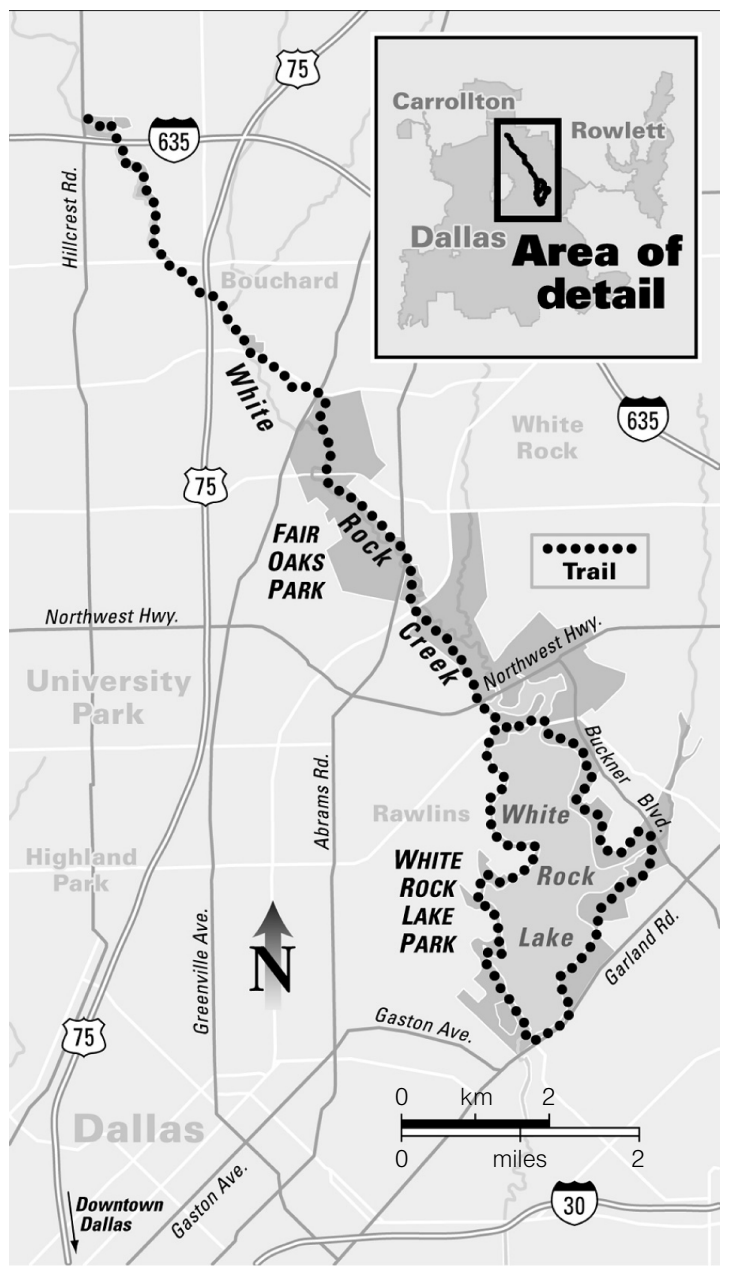

Figure 3. Map of the Dallas White Rock Lake Trail.

Lakewood (with its up-market restaurants, wine bars, and heritage craftsman and ranch houses); Forest Hills (due south of the lake) where mansions front onto Garland Road; Old Lake Highlands - a post-Second-World-War community with a strong neighborhood association - and Lake Park Estates and Lochwood, with their 1950s and 1960s era ranch-style houses; and Casa Linda with its Spanish Revival style architecture. Generally, the northern and southernmost portions of White Rock Lake Trail are situated in wealthy, mostly single-family housing areas with a predominantly white, middle age to elderly, college-educated population. In contrast, the trailside neighborhoods located along the central portion of the trail are poorer, as indicated by the high scores on the poverty component and lower rates of vehicle ownership, and characterized by land-use diversity.

(3) The Los Angeles River Trail (figure 4) runs along this waterway, which is channelized and in many areas has steep concrete banks, and curves around along the beach at Long Beach. The trail has several segments: the Long Beach Shoreline Trail segment was completed in 1988 and the Vernon to Long Beach segment, along the Los Angeles River, was completed in 1977 (City of Long Beach, 2009; Gumprecht, 2001, pages $284-296$ ). The portion of the trail studied here extends from older inner-ring 


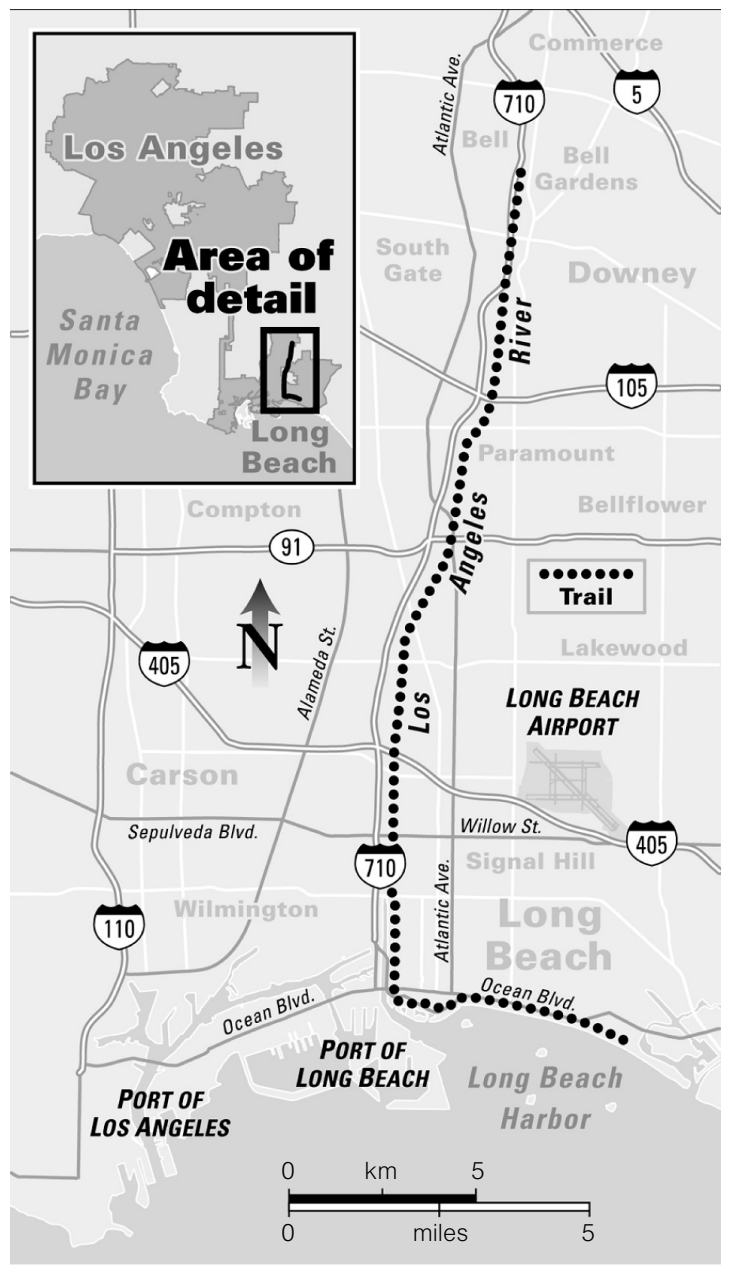

Figure 4. Map of Los Angeles River Trail.

suburbs in the north to the beach area of Long Beach. In some stretches the trail runs immediately parallel to a major interstate highway (the 710) as well as the river. Apart from the obvious barriers of the river channel and freeway, the built environment is characterized by low street connectivity. Northern trailside neighborhoods begin near the Santa Ana Freeway (Interstate 5), in the industrial City of Commerce. To the south are Maywood, Bell, Bell Gardens, Southgate, Lynwood, Paramount, and Compton. Once predominantly white, most residents in these neighborhoods are middle aged, working class, and Asians and Pacific islanders, and other race groups (primarily Hispanic), living in multifamily housing. To the south, neighborhoods become poorer, with families with children and young adults living in overcrowded housing conditions. At the Long Beach end the trail abruptly transitions into a well-kept beach path, skirting along the edge of downtown Long Beach past the aquarium, restaurants, and convention hotels. Except for the beach district, trail maintenance is poor with little formal landscaping. Upper-section trail users pass by decrepit warehouses and water towers, disused rail lines, and weed-filled lots. Hugging the concrete levees of the Los Angeles River, the midsections are covered in graffiti, littered with broken glass, and shelter homeless people under freeway overpasses. Further south, the trail passes 
through desolate stretches of freeway-dominated landscape, relieved by the occasional horse stable or stretch of bird-filled marshland.

Evidently the three trailside neighborhoods are diverse not only in terms of physical and environmental characteristics, but also with respect to their sociodemographic patterns and built-environmental features. All of these characteristics in combination with certain individual traits and perceptions of trail environments among residents of trail-adjacent neighborhoods may have differential impacts on trail use decisions and overall levels of trail use in each city. The next set of results describes the individual trends in trail use on the basis of the survey statistics, and the differences between trail users and nonusers in terms of their socioeconomic status, health status, and the perceptions of trail environment.

\section{Individual patterns of trail use}

The total of 490 individuals living in trail-adjacent neighborhoods participated in the survey. Seventy percent of respondents reported having ever used the trail; $50 \%$ used the trail for recreation at least once per month; while $18 \%$ used the trail for transportation at least once per month. The reported use rates across the three trails were substantially different: Chicago Lake Front Trail was the most heavily utilized trail$71 \%$ of respondents used the trail for recreation and $36 \%$ for transport; $49 \%$ of respondents in Dallas used the Dallas White Rock Lake Trail for recreation and 9\% for transport; while in Los Angeles only 16\% of respondents along the LA River Trail utilized the trail for recreation and 5\% for transport (table 1).

The results of $\chi^{2}$ and $t$-tests for differences in sociodemographic characteristics, health status, intrinsic motivation, and perceptions of trail environment between the trail users and nonusers are summarized in table 2 . These results indicate that singleparent households with children are least likely to use a trail (43\% versus $66 \%-84 \%)$ and that respondents with higher income and educational attainment are more likely to be trail users. Race/ethnicity and sex are not related to the probability of trail use. Respondents reporting better general health are more apt to be trail users, and so are the respondents with higher intrinsic motivation for physical activity. Compared with nonusers, trail users perceive that they have superior access to local services, neighborhood surroundings, streetscapes, and trail safety. Perceived neighborhood safety, however, is not significantly different for trail users and nonusers on the basis of these bivariate statistical tests.

Table 1. Patterns of trail use.

$\begin{array}{llll}\text { Chicago } & \text { Dallas } & \text { Los Angeles } & \text { All cities } \\ (N=186) & (N=161) & (N=143) & (N=490)\end{array}$

\section{Trail use}

Yes $(\%)$

No $(\%)$

Monthly use recreation

Never use (\%)

Use $(\%)$

$1-10$ times $(\%)$

$11+$ times $(\%)$

\section{Transportation}

Never use (\%)

Use $(\%)$

$1-10$ times $(\%)$

$11+$ times $(\%)$
90

10

90
10

\section{2}

28

31

69

55

14

64

3
52

48

82

18

16

2
73

27

52

48

38

10

83

18

16

2 
Table 2. Individual differences between trail users and nonusers.

\begin{tabular}{|c|c|c|c|c|}
\hline \multirow[t]{2}{*}{ Individual characteristic } & \multicolumn{2}{|l|}{ Trail use } & \multicolumn{2}{|c|}{$\chi^{2}$ statistic } \\
\hline & $\begin{array}{l}\text { ever used } \\
\text { trail }(\%)\end{array}$ & $\begin{array}{l}\text { never used } \\
\text { trail }(\%)\end{array}$ & value & probability \\
\hline
\end{tabular}

\section{Household composition}

(1) Single

(2) Unrelated adults

$\begin{array}{ll}66 & 34 \\ 84 & 16 \\ 72 & 28 \\ 43 & 57 \\ 81 & 19 \\ 76 & 24\end{array}$

(3) Couple with children $<18$ years

(4) Single parent with children $<18$ years

(5) Two parents with children $<18$ years

(6) Multigenerational household

\section{Education}

(1) High school or less

$50 \quad 50$

(2) Some college

(3) College graduate

$\begin{array}{ll}59 & 41 \\ 74 & 26\end{array}$

(4) Graduate school

26
18

\section{Race}
(1) Black
(2) Other
(3) White

Ethnicity/Hispanic

Sex

\section{General health}
(1) Poor
(2) Fair
(3) Good
(4) Very good
(5) Excellent

$\begin{array}{ll}61 & 39 \\ 65 & 35 \\ 73 & 27\end{array}$

Intrinsic motivation $^{\mathrm{a}}$
(1) Low
(2) Moderate
(3) High

Access to services ${ }^{\mathrm{b}}$
(1) Poor
(2) Good
(3) Excellent

Neighborhood surroundings ${ }^{\mathrm{b}}$
(1) Poor
(2) Good
(3) Excellent

Street quality ${ }^{\mathrm{b}}$
(1) Average
(2) Above average

Neighborhood safety ${ }^{\mathrm{b}}$

(1) Poor

(2) Good

(3) Excellent

Trail safety ${ }^{\mathrm{b}}$
(1) Poor
(2) Good
(3) Excellent

$\begin{array}{ll}50 & 50 \\ 61 & 39 \\ 63 & 37 \\ 67 & 33 \\ 84 & 16\end{array}$

$4.1493 \quad 0.1256$

35
27

$24.5765<0.0001$

$2.1636 \quad 0.1413$

$2.648 \quad 0.1037$

$16.2175 \quad 0.0027$

39

37

33

$47 \quad 53$

53
72

$15.1504 \quad 0.0005$

$24 \quad 76$

$\begin{array}{llll}66 & 34 & 9.0776 & 0.0107 \\ 62 & 38 & & \\ 77 & 23 & & \end{array}$

$\begin{array}{llll}51 & 49 & 13.7173 & 0.0011 \\ 73 & 27 & & \\ 75 & 25 & & \\ & & & \\ 63 & 37 & & \\ 74 & 26 & & \\ & & & \\ 65 & 35 & & \\ 75 & 25 & & \\ 68 & 32 & & \\ & & & \\ 65 & 35 & & \\ 77 & 23 & & \\ 72 & 28 & & \end{array}$

a Assessed using four self-report items listing reasons for exercise and rated (eg "Because it's fun") on a seven-point scale ranging from 'not at all true' to 'very true'.

${ }^{b}$ Assessed using self-report items in which a series of statements, varying in number for each scale, were rated for agreement on a scale from 'strongly disagree' to 'strongly agree'. 


\section{Model results}

Initially, we examined the individual-level and neighborhood-level correlates of urban trail use independently of each other. A correlation matrix with the most significant associations between the individual-level variables and total time on a trail is presented in table 3. These results suggest that the perceived distance to a trail had the strongest negative association with total time spent on the trail $(r=-0.23)$, indicating that the smaller the perceived distance to the trail, the greater was the total time of trail use per week.

Table 3. Pearson correlation matrix for individual-level and neighborhood-level variables and total time on trail.

\begin{tabular}{lclr}
\hline Individual variables & Total time & Neighborhood variables & Total time \\
\hline Motivation & $0.21(<0.0001)$ & Age & $-0.31(<0.0001)$ \\
Facility & $0.21(<0.0001)$ & Working class & $-0.35(0.00)$ \\
Access & $0.12(0.01)$ & Overcrowding & $-0.30(0.00)$ \\
Streets & $0.16(0.00)$ & Vehicles & $-0.17(0.00)$ \\
Surroundings & $0.13(0.01)$ & Commute $<30$ minutes & $-0.14(0.00)$ \\
Neighborhood safety & $0.11(0.03)$ & Land-use mix & $0.20(<0.0001)$ \\
Trail safety & $0.13(0.01)$ & Connectivity & $-0.22(<0.0001)$ \\
General health & $0.20(<0.0001)$ & Barriers & $-0.19(<0.0001)$ \\
Perceived distance to trail & $-0.23(<0.0001)$ & $\begin{array}{l}\text { Green cover (normalised } \\
\text { difference vegetation }\end{array}$ & $0.14(0.00)$ \\
& & index)
\end{tabular}

Note: $\operatorname{Pr}>|r|$ is shown in parentheses.

Among the positive associations, intrinsic motivation for physical activity, general health status, and availability of recreational facilities have the strongest correlation with the total time spent on the trail $(r=0.21)$. Other significant and positive associations presented in table 3 suggest that perception matters: the better the perceived trail access and the better the perceived quality of streets, the greater was the time of trail use; and the greater the perceived neighborhood social cohesion, and perceived neighborhood as well as trail safety, the greater the total time spent on the trail.

Table 3 also reveals the most significant associations between neighborhood-level variables and total time on the trail. The neighborhood variables considered here represent factors that explained the greatest amount of variance across the trails in terms of the sociodemographic and built-environmental characteristics of the surrounding neighborhoods. The significant and positive associations with total trail use time include LUM and a green cover indicator [normalized difference vegetation index (NDVI), an indicator of vegetative cover based on satellite imagery]. Age, working class, overcrowding, and, surprisingly, street connectivity have the strongest negative correlations with the total time spent on the trail.

The findings from the correlation analyses informed the selective input of variables into both multilevel logistic and Tobit models. The individual-level variables considered were intrinsic motivation, general health, perceived distance to trail, and trail safety because of their strong association with total time spent on the trail. At the neighborhood level, the PCA-derived component, working class, was chosen to represent the conceptual category of income and poverty because this component incorporates a variety of indicators including income, poverty, education, and housing ownership; other related variables (multifamily housing, overcrowding, and vehicle ownership) were excluded to control for multicolinearity. Among the environmental variables, 
commuting time, LUM, connectivity, physical barriers to the trail, and green cover as measured by NDVI were all initially included; LUM and NDVI were subsequently removed from the model as they did not contribute significantly to the outcome. These findings run counter to some studies in the literature, and warrant further investigation.

The results obtained through the multilevel logistic model (table 4) suggest that intrinsic motivation, perceived trail safety, and perceived distance (in miles) between home and trail were individual-level factors significantly related to the probability of trail use $(p>0.05)$; self-reported general health was not significant. At the neighborhood level, in contrast to initial correlation results, connectivity of the street network was positively related to trail use probability. As expected, working-class status and barriers to trail use were negatively related $(p<0.05)$.

Table 4. Multilevel logistic regression model with dichotomous dependent variable (trail use/no use).

\begin{tabular}{|c|c|c|c|c|c|c|c|c|}
\hline \multirow[t]{2}{*}{ Effect } & \multicolumn{8}{|c|}{ Solution for fixed effects } \\
\hline & estimate & $\begin{array}{l}\text { standard } \\
\text { error }\end{array}$ & DF & $t$-value & $\operatorname{Pr}>|t|$ & alpha & lower & upper \\
\hline Intercept & -4.4959 & 1.0827 & 68 & -4.15 & $<0.0001$ & 0.05 & -6.6565 & -2.3354 \\
\hline Motivation & 0.3008 & 0.101 & 247 & 2.98 & 0.0032 & 0.05 & 0.1019 & 0.4998 \\
\hline General health & 0.2316 & 0.1529 & 247 & 1.51 & 0.1311 & 0.05 & -0.0695 & 0.5328 \\
\hline $\begin{array}{l}\text { Perceived distance } \\
\text { to trail }\end{array}$ & -0.3923 & 0.1888 & 247 & -2.08 & 0.0387 & 0.05 & -0.764 & -0.0205 \\
\hline $\begin{array}{l}\text { Trail safety } \\
\text { SES: }\end{array}$ & 1.1782 & 0.3251 & 247 & 3.62 & 0.0004 & 0.05 & 0.5379 & 1.8186 \\
\hline working class & -0.4971 & 0.1701 & 68 & -2.92 & 0.0047 & 0.05 & -0.8365 & -0.1578 \\
\hline $\begin{array}{l}\text { Connectivity: } \\
\text { low to moderate }\end{array}$ & 0.6524 & 02528 & 68 & 258 & 0012 & 005 & 01470 & 1.1569 \\
\hline Barriers & -0.0001 & $<0.0001$ & 68 & -2.26 & 0.0273 & 0.05 & -0.0002 & $<-0.0001$ \\
\hline Chicago & 1.7485 & 0.514 & 68 & 3.4 & 0.0011 & 0.05 & 0.7228 & 2.7741 \\
\hline Dallas & 1.0932 & 0.5404 & 68 & 2.02 & 0.047 & 0.05 & 0.0149 & 2.1715 \\
\hline
\end{tabular}

The Tobit model had similar results, with the exception that self-reported general health status was significant in explaining the total time spent on the trail per week $(p<0.05)$ (table 5). Decomposition of the Tobit coefficients revealed that efforts to increase perceived trail safety and decrease perceived distance to the trail would have the biggest influence in converting nonusers to users, while also having the largest influence on increasing the time spent per week on the trail among trail users.

Specifically, these results suggest that a one-unit improvement in perceived trail safety on a five-part scale would increase the time spent on the trail each week by 55.24 minutes - almost one hour-among those already using the trail. This should be treated as a rough estimate that may vary depending on where an individual is positioned on the perceived trail safety scale: a one unit change at the low end of the ordinal perceived trail safety scale may not be the same as at the high end. Similarly, if the perceived proximity to the trail were to go down by one mile, the time spent on the trail among existing trail users would increase by 52.24 minutes again, almost a full hour. These same changes in perceived safety and distance to the trail would increase the probability that nonusers would begin using the trail by $10.4 \%$ and $9.8 \%$, respectively. 
Table 5. The tobit model with decomposition, with time spent on the trail as dependent variable.

\begin{tabular}{|c|c|c|c|c|c|c|c|c|c|c|}
\hline \multirow[t]{3}{*}{ Parameter } & \multirow[t]{3}{*}{ DF } & \multicolumn{7}{|c|}{ Analysis of parameter estimates } & \multirow{2}{*}{\multicolumn{2}{|c|}{$\frac{\text { Decomposition }}{\text { decomposition coefficient }}$}} \\
\hline & & \multirow[t]{2}{*}{ estimate } & \multirow{2}{*}{$\begin{array}{l}\text { standard } \\
\text { error }\end{array}$} & \multirow{2}{*}{\multicolumn{2}{|c|}{$95 \%$ confidence level }} & \multirow[t]{2}{*}{$\chi^{2}$} & \multirow[t]{2}{*}{$\operatorname{Pr}>\chi^{2}$} & \multirow{2}{*}{$\begin{array}{l}\text { standardized } \\
\text { coefficient }\end{array}$} & & \\
\hline & & & & & & & & & trail use & nonuse \\
\hline Intercept & 1 & -1770.39 & 374.3037 & -2504.01 & -1036.77 & 22.37 & $<0.001$ & & & \\
\hline Motivation & 1 & 109.6077 & 28.8959 & 52.9728 & 166.2425 & 14.39 & 0.0001 & 0.2582 & 34.8673 & 0.0654 \\
\hline General health & 1 & 96.4185 & 45.9043 & 6.5108 & 186.4522 & 4.42 & 0.0356 & 0.1398 & 30.6917 & 0.0575 \\
\hline $\begin{array}{l}\text { Perceived distance } \\
\text { to trail }\end{array}$ & 1 & -164.225 & 60.1541 & -282.125 & -46.325 & 7.45 & 0.0063 & -0.1736 & -52.2415 & -0.0979 \\
\hline $\begin{array}{l}\text { Trail safety } \\
\text { SES: }\end{array}$ & 1 & 173.6427 & 88.5732 & 0.0424 & 347.243 & 3.84 & 0.0499 & 0.1280 & 55.2374 & 0.1035 \\
\hline working class & 1 & -113.384 & 50.3926 & -212.151 & -14.616 & 5.06 & 0.0244 & -0.1653 & -36.0685 & -0.0676 \\
\hline $\begin{array}{l}\text { Commute less than } \\
30 \text { minutes }\end{array}$ & 1 & -83.5557 & 40.5794 & -163.09 & -4.0216 & 4.24 & 0.0395 & -0.1209 & -26.5799 & -0.0498 \\
\hline Nodes & 1 & 6.9724 & 2.0333 & 2.9872 & 10.9577 & 11.76 & 0.0006 & 0.6166 & 2.2180 & 0.0042 \\
\hline Length feet & 1 & -0.0321 & 0.0159 & -0.0632 & -0.001 & 4.09 & 0.0431 & -0.2245 & -0.0102 & $-1.914 \times 10^{-5}$ \\
\hline Chicago & 1 & 755.4202 & 188.047 & 386.8548 & 1123.986 & 16.14 & $<0.0001$ & 0.5486 & 240.3064 & 0.4504 \\
\hline Dallas & 1 & 708.0416 & 224.6845 & 267.668 & 1148.415 & 9.93 & 0.0016 & 0.4976 & 225.2348 & 0.4222 \\
\hline Scale & 1 & 668.9687 & 32.1546 & 608.8244 & 735.0546 & & & & & \\
\hline
\end{tabular}


Furthermore, increasing intrinsic motivation by one unit on a seven-part scale increases trail minutes by 34.86 minutes, more than half an hour, while increases in general health status by one unit on a 5-part scale would increase trail use by 30.69 minutes among those already using the trail. (Again, note that these times may vary depending on position on the seven-part ordinal scale since relationships between motivation or general health status and trail time may not be linear.) Among nonusers, such changes would increase their probability of becoming trail users by $6.5 \%$ and $5.6 \%$, respectively. (It should also be noted that an increase in trail use due to other reasons might increase reported general health status, which would then feedback to increase trail use even more.)

Because of the large differences in prevalence of trail use across the three cities, living in either Chicago or Dallas is associated with huge impacts on the total time spent at a trail, 240 more minutes if one is a Chicagoan, and 225 more minutes if one is from Dallas-compared with Los Angeles. For nontrail users, moving to the Chicago trail front would increase the probability of trail use by $45 \%$, and moving to the Dallas trail area would increase it by $42 \%$.

\section{Discussion}

Our study of the three multipurpose urban trails located in Chicago, Dallas, and Los Angeles support the conceptual model of trail use, suggesting that several intersecting individual and trail-specific characteristics - both objective and perceived - influence multipurpose trail use decisions and overall levels of use among those living in trailside neighborhoods. The three urban trail neighborhoods are different not only in terms of their physical and environmental characteristics, but also with respect to their sociodemographic patterns and built-environmental features. Chicago's Lake Front Trail has the most attractive landscape as compared with the other two trails, and is situated in predominantly middle-class neighborhoods characterized by land-use diversity and significant opportunities for transport. The Dallas White Rock Trail is also fairly attractive, if not so formally designed and landscaped as Chicago, and large portions of the trail traverse wealthy neighborhoods and areas with diverse land uses. The southern portion of the Los Angeles River Trail is very mixed. Although the southern end runs along the Pacific Ocean and its scenic beaches, the northern end is by far the least attractive of any of the trails, surrounded by socioeconomically disadvantaged communities and blighted environments. Given the substantial diversity of the three trails in terms of their sociodemographic and built-environmental characteristics, it came as no surprise to learn, from the survey statistics, that the Chicago Lake Front Trail was the most heavily utilized trail among nearby residents while the Los Angeles River Trail was the least utilized.

The subsequent set of bivariate results provided an initial understanding of the differences between trail users and nonusers across the three trails, on the basis of the survey data. We learned that, in general, respondents with higher income, educational attainment, and better general health are more likely to be trail users. Furthermore, compared with nonusers, trail users perceive that they have superior access to services, and more attractive neighborhood surroundings. In addition, trail use was more common in some types of neighborhoods than in others. Generally, areas with higher socioeconomic status, older residents, more green cover, fewer physical barriers to the trail, and where workers have shorter commutes had higher rates of trail use. Interestingly, race and ethnicity were not significantly related to the prevalence of trail use, and nor was gender.

These findings were complemented by the multilevel logistic and Tobit models that considered the impact of individual-level and neighborhood-level influences on trail 
use simultaneously. These findings confirm our hypotheses, and revealed that intrinsic motivation to engage in physical activity, perceived distance to the trail, and perceived trail safety were the most important individual predictors of trail use. Moreover, as motivation increases, so does the time spent on the trail each week, as well as the probability that nonusers will become trail users. Furthermore, trail users will likely spend more time at a trail if the perceived distance between their home and the trail is shorter and if perceived trail safety is higher. Increases in perceived trail safety and reductions in perceived miles to the trail would also have the biggest influence in converting nonusers to users. While reducing the actual distance of residential neighborhoods to urban trails by as much as a mile could occur only as the result of a major trail-building program, reducing perceived distances for those living reasonably close to a trail, through signage for example, could be effective. Similarly, additional trail security and landscape features such as lighting that increase perceived safety would have a major impact on trail use. At the neighborhood level, the presence of barriers suppresses trail use and their extent adversely influences the time people spent on a trail as well as the probability that a nonuser will start using the trail. Street connectivity also affects trail utilization, with more walkable neighborhoods offering better access to the trail and increasing the likelihood that users will spend more time on the trail. Social class is another important predictor of trail use-trail use in wealthier neighborhoods is typically higher than in working-class or more disadvantaged areas.

The present study replicates and extends several findings from past studies. Distance to trail has shown an inverse relationship with trail use for both perceived and objective measures in several studies (Abildso et al, 2007; Brownson et al, 2000; Krizek et al, 2007; Merom et al, 2003; Troped et al, 2001). Our findings replicate this prior research and strengthen past findings by demonstrating a distance effect across a wide range of users, geographic regions, and trail characteristics. Our results showed that socioeconomic status was positively associated with likelihood of trail use and time on a trail, also replicating past findings for a positive association between income, education (Brownson et al, 2000; Lindsey et al, 2006; 2008), and trail use. In the present study we found that barriers had an inverse relationship with the likelihood of trail use. Although physical barriers have not been explored extensively for their association with trail use, past studies have found inverse associations with trail traffic counts for slope of trail (Lindsey et al, 2008), with self-reported trail use for degree of slope of the route taken through the neighborhood to reach the trail (Troped et al, 2001), and for litter and noise for associations with observational trail counts (Reynolds et al, 2007). Commute time, significant in the present study, might also be conceptualized as a barrier with longer commutes reducing time available for recreational physical activity including physical activity on trails. Additional work on the role of barriers in determining trail use is warranted and may provide specific guidance for the design of trails and the promotion of trail use. Finally, the trails used in this research were located in three distinct geographic regions of the United States including the South Central, the Midwest, and the West. This diversity in geographic location is rare with most studies utilizing one trail, or one trail system, in a single region of the country (Abildso et al, 2007; Evenson et al, 2005; Gobster, 1995; Krizek et al, 2007; Lindsey et al, 2001; 2008; Merom et al, 2003; Troped et al, 2001). The approach utilized in our study enhances confidence that the findings, including those that replicate earlier studies, can be generalized across regions that vary in climate, governance, and history and culture.

Several of the significant correlates of likelihood of trail use and time on trail identified in the present study have not been extensively examined in past studies. We are not aware of another paper obtaining a correlation between intrinsic motivation and trail use. Our study shows that higher levels of intrinsic motivation are strongly 
associated with both the likelihood of trail use and time on the trail. Efforts to increase trail use may need to increase individual motivation for physical activity along with the implementation of policies and campaigns to alter trail quality, availability, and awareness. Explorations of perceived health and its influence on trail use are also rare. Troped and colleagues tested the influence of physical activity limitations and found this variable to be negatively associated with use of an urban trail (Troped et al, 2001). The positive association between general health and time spent on trail in the present study is similar to that obtained by Troped et al and suggests a need to further explore health status as a moderator of trail use and perhaps to examine ways in which trail accessibility can be facilitated for those with physical impairments. Our findings for connectivity are somewhat unique with few studies testing the association of the built characteristics of the neighborhoods surrounding trails with trail use. Work on surrounding neighborhoods by Lindsey and colleagues has shown that an increased percentage of land devoted to commercial purposes and greater parking availability are linked to increased trail traffic, as measured using infrared counters (Lindsey et al, 2006; 2008). Finally, safety has been examined in its relationship with physical activity but, surprisingly, trail safety has not been directly tested as a correlate of trail use. In the present study, perceived trail safety exhibited a strong association with use of trail.

It is worth noting that several variables found significant in past studies of trail use were not significant in the present study. Several of these variables are demographic with age, gender, and race all demonstrating associations in past studies (Brownson et al, 2000; Lindsey et al, 2006; 2008; Troped et al, 2001). Greenness of the trail has been shown to be positively associated with trail traffic counts in studies by Lindsey et al. Although our study did not use trail greenness, a measure of neighborhood green cover (NDVI) was not associated with likelihood of trail use or time on trail (Lindsey et al, 2006; 2008).

Clearly, more work remains to be done in terms of both conceptualization and measurement. For example, why might there be differences in perceived and objective measures of neighborhood characteristics? How do specific aspects of the trail, including the nature and types of activities of its general user population, influence trail use decisions? How might the distribution of destinations such as workplaces, in relation to trail facilities as well as public transport, shape decisions to use urban trails for transportation purposes? Given the importance of proximity and perceived safety, how do objectively measured indices of trail access and crime rates shape trail use decisions? And do individuals use trails because they have better health status or is their health status better because of their trail use and associated physical activity? Such questions require more complex research designs and, following Evenson et al (2005), longitudinal analysis that can more clearly answer questions about causation.

Especially if supported by additional findings, our results also may help guide public policy decisions about urban trail infrastructure investment and help trail authorities shape strategies to maximize multiuse trail activities. Decision makers should consider enhancing perceived safety by providing additional security, incorporating features such as street lights and access point signage, or by insuring that trails are well landscaped and maintained, since such features have been shown elsewhere to shape perceptions of safety (Brownlow, 2006); social interventions such as walking clubs might also be effective in increasing perceived safety and encouraging trail use. Similarly, improving connectivity and hence neighborhood walkability may make existing trails easier to access, while designing routes through neighborhoods that minimize barriers to trail access, such as through-block pathways, would be helpful in encouraging trail use. Perhaps most of all, given the importance of 
distance, urban planners should incorporate urban trails in plans for new and existing community designs.

Our results also have implications for health promotion professionals, whether in local government, school districts, or health agencies. Trail use rates differ substantially depending especially on individual motivation to engage in physical activity. Strategies to enhance motivation - by providing social opportunities for trail activities through schools and park and recreation department programs, encouraging churches or nonprofit organizations to establish walking clubs, or creating health communications strategies designed to increase awareness regarding the health benefits of trail usemay result in greater propensity to use urban trails as well as to spend more time on the trail.

Interventions designed to improve general health are vital for obvious reasons and any such improvements could translate into increased trail use and physical activity. As noted, it is also possible that residents that use urban trails perceive themselves as being in better health because their trail use offers health benefits, reinforcing the benefits of urban trails as public health interventions. Thus some strategies to encourage those who perceive themselves as being in moderate health to use nearby trails could result in improved self-reported health status. This means that health communications programs that emphasize the benefits of even relatively limited increments of walking - and connect this to information about trail access, attractiveness, and opportunities for social interaction - could be valuable interventions.

Trail use rates and time spent on the trail are lower in working-class neighborhoods. Residents in such neighborhoods are less apt to have health insurance or adequate access to health care, and such evidence indicates that rates of obesity and related health problems are higher. Also, such communities are often park poor (because of either absolute lack of open space or congestion of existing facilities), and face challenges with respect to access to fresh, healthy, and affordable food. Interventions designed to encourage urban trail use may be particularly appropriate in such neighborhoods, including: health communications strategies; better trail maintenance, landscaping, signage, and lighting; and efforts to reduce physical barriers, increase connectivity, and enhance the attractiveness of local surroundings.

\section{References}

Abildso C, Zizzi S, Abildso L, Steele J, Gordon P, 2007, "Built environment and psychosocial factors associated with trail proximity and use" American Journal of Health Behavior 31 374-383

Anderson L H, Martinson B C, Crain A L, Pronk N P, Whitebird R R, Fine L J, O'Connor P J, 2005 , "Health care charges associated with physical inactivity, overweight, and obesity"

Public Health Research, Practice, and Policy $21-12$

Brownlow A, 2006, "An archaeology of fear and environmental change in Philadelphia" Geoforum $37227-245$

Brownson R C, Housemann R A, Brown D R, Jackson-Thompson J, King A C, Malone B R, Sallis J F, 2000, "Promoting physical activity in rural communities: walking trail access, use, and effects" American Journal of Preventive Medicine 18235 - 241

Brownson R C, Baker E A, Boyd R L, Caito N M, Duggan K, Housemann R A, Kreuter M W, Mitchell T, Motton F, Pulley C, Schmid T L, Walton D, 2004, "A community-based approach to promoting walking in rural areas" American Journal of Preventive Medicine 27 28-34

Calle E, Kaaks R, 2004, "Overweight, obesity and cancer: epidemiological evidence and proposed mechanisms" Nature Reviews Cancer 4579 - 591

City of Long Beach, 2009, "Shoreline pedestrian bikepath", City of Long Beach Parks, Recreation and Marine, http://www.longbeach.gov/park/recreation/sports/bike_paths.asp

Dannenberg A L, Jackson R J, Frumkin H, Schieber R A, Pratt M, Kochtitzky C, 2003, "The impact of community design and land-use choices on public health: a scientific research agenda" American Journal of Public Health 93 1500 - 1508

Deckelbaum R J, Williams C L, 2001, "Childhood obesity: the health issue" Obesity Research 9 $239 \mathrm{~S}-243 \mathrm{~S}$ 
Evenson K R, Herring A H, Huston S L, 2005, "Evaluating change in physical activity with the building of a multi-use trail" American Journal of Preventive Medicine 28 177-185

Ewing R, Schmid T, Killingsworth R, Zlot A, Raudenbush S, 2003, "Relationship between urban sprawl and physical activity, obesity, and morbidity" American Journal of Health Promotion $1847-57$

Frank L D, Engelke P O, Schmid T L, 2003 Health and Community Design: The Impact of the Built Environment on Physical Activity (Island Press, Washington, DC)

Frank L D, Andresen M, Schmid T, 2004, "Obesity relationships with community design, physical activity, and time spent in cars" American Journal of Preventive Medicine 2787 - 96

Frumkin H, 2003, "Healthy places: exploring the evidence" American Journal of Public Health 93 $1451-1456$

Furuseth, O J, 1989, "Greenway user characteristics and attitudes: a study of the McAlpine Greenway, Charlotte, North Carolina”, paper presented at International Conference on Parkways, Greenways, and Riverways, Asheville, NC; copy available from author, Department of Geography and Earth Sciences, University of North Carolina, Charlotte, NC

Furuseth O J, Altman R, 1991, "Who's on the greenway: socioeconomic, demographic, and locational characteristics of greenway users" Environmental Management 15329 - 336

Gobster P, 1988, "Urban bicycle trails: use patterns and user preferences" Trends $2521-25$

Gobster P, 1995, "Perception and use of a metropolitan greenway system for recreation" Landscape and Urban Planning 33401 - 413

Gobster P, 2005, "Recreation and leisure research from an active living perspective: taking a second look at urban trail use data" Leisure Sciences $27367-383$

Godbey G, Caldwell L, Floyd M, Payne L, 2005, "Contributions of leisure studies and recreation and park management research to the active living agenda" American Journal of Preventive Medicine $\mathbf{2 8} 150-158$

Groenewegen P, van der Berg A, de Vries S, Verheij R, 2006, "Study protocol vitamin G: effects of green space on health, well-being, and social safety. Rails-to Trails Conservancy: benefits of trails", http://www.railstotrails.org/whatwedo/railtrailinfo/benefits.html\#health

Gumprecht B, 2001 The Los Angeles River: Its Life, Death and Possible Rebirth (Johns Hopkins University Press, Baltimore, MD)

Handy S L, Boarnet M G, Ewing R, Killingsworth R E, 2002, "How the built environment affects physical activity: views from urban planning" American Journal of Preventive Medicine 23 64-73

Hoener C M, Brennan L K, Brownson R C, Handy S L, Killingsworth R, 2003, "Opportunities for integrating public health and urban planning approaches to promote active community environments" American Journal of Health Promotion $1814-20$

Hunter W, Huang H, 1995, "User counts on bicycle lanes and multiuse trails in the United States" Transportation Research Record number 1502, 45- 57

Huston S, Evensonm K, Borsm P, Gizlicem Z, 2003, "Neighborhood environment, access to places for activity, and leisure-time physical activity in a diverse North Carolina population" American Journal of Health Promotion 1858 - 69

Jackson R J, 2003, "The impact of the built environment on public health" American Journal of Public Health $931382-1384$

Janz K F, Burns T L, Levy S M, 2005, "Tracking of activity and sedentary behaviors in childhood: the Iowa bone development study" American Journal of Preventive Medicine 29171 - 178

Krizek K J, El-Geneidy A, Thompson K, 2007, "A detailed analysis of how an urban trail system affects cyclists' travel" Transportation $34611-624$

Lee C, Moudon A V, 2004, "Physical activity and environment research in the health field: implications for urban and transportation planning practice and research" Journal of Planning Literature 19147 - 181

Lindsey G, 1999, "Use of urban greenways: insights from Indianapolis" Landscape and Urban Planning $45145-157$

Lindsey G, Nguyen D, 2004, "Use of greenways trails in Indiana” Journal of Urban Planning Development $130213-218$

Lindsey G, Maraj M, Kuan S, 2001, "Access, equity, and urban greenways: an exploratory investigation" The Professional Geographer 53332 - 346

Lindsey G, Han Y, Wilson J, Yang J, 2006, "Neighborhood correlate of urban trail use" Journal of Physical Activity and Health $3139-157$

Lindsey G, Wilson J, Yang J, Alexa C, 2008, Urban greenways, trail characteristics and trail use: implications for design" Journal of Urban Design $1353-79$ 
Lopez R, 2004, "Urban sprawl and risk for being overweight or obese" American Journal of Public Health $941574-1579$

Lopez-Zetina J, Lee H, Friis R, 2006, "The link between obesity and the built environment. Evidence from an ecological analysis of obesity and vehicle miles of travel in California" Health and Place 12 656-664

Merom D, Bauman A, Vita P, Close G, 2003, "An environmental intervention to promote walking and cycling - the impact of a newly constructed rail trail in Western Sydney" Preventative Medicine $36235-242$

Reynolds K, Wolch J, Byrne J, Chou C P, Feng G, Weaver S, Jerrett M, 2007, “Trail characteristics as correlates of urban trail use" Journal of Health Promotion 21 - 12

Sallis J F, Prochaska J J, Taylor W C, 2000, "A review of correlates of physical activity of children and adolescents" Medicine and Science in Sports and Exercise $32963-975$

Spruijt-Metz D, Reynolds K D, Wolch J, Jerrett M, Byrne J, Hseih S, Ranell M, Bin X, Wang L, Chou C P, forthcoming, "Development, reliability and validity of an urban trail use survey" American Journal of Health Promotion

Srinivasan S, O'Falon L, Deary A, 2003, "Creating health communities, healthy homes, healthy people: a research agenda on the built environment and public health" American Journal of Public Health 931446 - 1450

Troped P, Saunders R, Pate R, 2001, "Associations between self-reported and objective physical environmental factors and use of a community rail-trail" Preventive Medicine $32191-200$

Wolter S, Lindsey G, 2001, "Indiana trails study", Summary Report, Eppley Institute for Parks and Public Lands, Indiana University, Bloomington, IN

\section{Appendix}

Table A1. Conceptual categorization of neighborhood-level variables.

\begin{tabular}{|c|c|}
\hline Conceptual & Variables \\
\hline $\begin{array}{l}\text { Demographics 1: } \\
\text { age }\end{array}$ & $\begin{array}{r}0-9 ; 10-19 ; 20-39 ; 40 \\
\quad 64 ; 65-74 ; 75+\text { years }\end{array}$ \\
\hline $\begin{array}{l}\text { Demographics } 2 \text { : } \\
\text { race }\end{array}$ & $\begin{array}{l}\text { White; Asian; African- } \\
\text { American; native } \\
\text { Hawaiian; American } \\
\text { Indian and Alaska } \\
\text { native; some other } \\
\text { race; and two or } \\
\text { more races }\end{array}$ \\
\hline
\end{tabular}

$\begin{array}{ll}\text { SES: working } & \text { Median income } \\ \text { class } & \text { Mean income }\end{array}$

Educational level: no education; some education; high school, some college; college; graduate

Poverty level: up to $99 \%$, Percentage of total $100-149 \%, 150-174 \%$, $175-184 \%, 185-199 \%$, and $200 \%$ and above

Housing tenure; owner-occupied, renter occupied

\section{US \$}

Percentage of total category

Percentage of total households of a households that are either owner

Metrics Source

$\begin{array}{lr}\text { Percentage of total } & \text { Census 2000 } \\ \text { population in each } & \text { (table SF3-P012) } \\ \text { age category } & \end{array}$

Percentage of total population in each racial category

Census 2000

(table SF3-P012) population aged $21+$ in each educational certain poverty level

Census 2000

(table SF3-P052) or renter occupied

Census 2000

(table SF3-P037)

Census 2000

(table SF3-P088)

Census 2000

(table SF3-H07) 
Table A1 (continued).

\begin{tabular}{llll}
\hline Conceptual & Variables & Metrics & Source \\
\hline $\begin{array}{l}\text { SES 2: housing } \\
\text { type }\end{array}$ & $\begin{array}{c}\text { Mobile, recreational } \\
\text { vehicle, boat; single } \\
\text { family; multifamily; } \\
1 \text { detached; 1 attached; }\end{array}$ & $\begin{array}{c}\text { Percentage of total } \\
\text { housing units of } \\
\text { a certain type }\end{array}$ & $\begin{array}{c}\text { Census 2000 } \\
\text { (table SF3-H30) }\end{array}$ \\
& $\begin{array}{l} \\
\text { and } 7+\text { units; }\end{array}$ & &
\end{tabular}

SES 3:

overcrowding

Occupants per room: $<1$, Percentage of total occupied households with specified number of occupants

SES 4:

Commute

Jobs/businesses

Land-use mix Parks

(LUM)

Connectivity

Barriers

Green Cover
Total neighborhood businesses

Employment

Number of vehicles: 0,1

$$
2+, 3+
$$

Work at home

Length of commute: $<10$ minutes, $10-29$ minutes, $30-59$ minutes, $60+$ minutes

Schools: elementary, middle, secondary, postsecondary

LUM: diversity of land use

Roadway intersections: nodes 4 through 8

Railroads
Rivers
Traffic

Traffic
Normalized difference vegetation index

Percentage of workers of $16+$ years of age who work at home

Percentage of workers of $16+$ of age who commute to work

Total number of businesses

Total number of employees

Total acres

Total number

LUM index (Frank et al, 2004)

Count of intersections with $4+$ nodes

Total length (feet)

Total length (feet)

Total average annual daily traffic
Census 2000

(table SF3-H020)

Census 2000

(table SF3-H44)

Census 2000

(table SF3-P31)
Index values -1.0 to +1.0

Info USA locationbased business data
Environmental Systems Research Institute (ESRI)
SCAG land-use data

ESRI business analyst data

ESRI business analyst dataset

\section{National Oceanic and Atmospheric Administration Advanced Very High Resolution Radiometer Satellite imagery}


Conditions of use. This article may be downloaded from the E\&P website for personal research by members of subscribing organisations. This PDF may not be placed on any website (or other online distribution system) without permission of the publisher. 